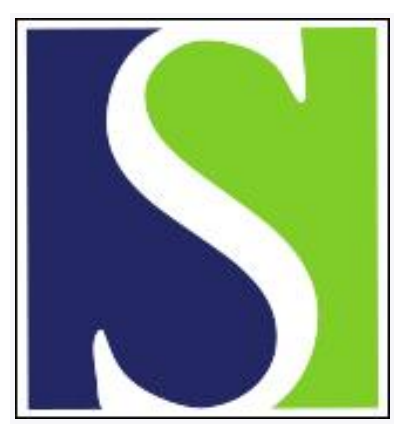

Scand J Work Environ Health 1990;16(1):29-38

https://doi.org/10.5271/sjweh.1825

Issue date: 1990

Subjective, behavioral and psychophysiological effects of noise.

by Kjellberg $A$

Affiliation: Institute of Occupational Safety and Health, Solna, Sweden.

This article in PubMed: www.ncbi.nlm.nih.gov/pubmed/2189217

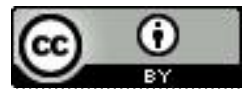




\title{
Subjective, behavioral and psychophysiological effects of noise
}

\author{
by Anders Kjellberg, $\mathrm{PhD}^{1}$
}

\begin{abstract}
KJELLBERG A. Subjective, behavioral and psychophysiological effects of noise. Scand J Work Environ Health 1990;16(suppl 1):29-38. The subjective and psychophysiological responses to noise and the effects of noise on performance have been reviewed in this article. Emphasis was placed on moderateintensity noise and on the effects relevant for occupational noise exposure. It was concluded that in many respects research presents a rather inconsistent picture of these effects. Still, it is evident that the nonauditory effects of noise may be serious enough to warrant as much general attention in the occupational setting as has for some time been accorded in residential settings.
\end{abstract}

Key terms: annoyance, performance, psychophysiology, review.

Noise is probably the most widespread problem in the physical work environment. Thus about $40 \%$ of the total work force consider themselves to be exposed to noise in Sweden. For male workers this figure is $68 \%$, and even among the white-collar workers the figure is about $25 \%$. Noise is also one of the environmental problems for which the psychological view points are of obvious importance. Thus, even the definition of noise, ie, "'unwanted sound," is stated in psychological rather than in physical terms. And although hearing damage of course is the most serious consequence of noise exposure, noise certainly creates problems at levels much lower than those at which such damage may occur.

The aim of the present paper was to review the psychological effects of noise where they are relevant for noise in the work environment. The limited space necessitates a very selective approach. Basic issues already adequately covered by previous reviews and books have, thus, often only been briefly noted with references to such works. The major basis for selection, however, was the emphasis on the work environment, since this aspect makes most psychological noise research of limited interest. Most of the applied psychological research on noise has dealt with problems in residential areas and is only partly generalizable to the work environment. Sleep disturbance is, eg, a major criterion of disturbance in residential areas, whereas it is irrelevant for almost all work situations. Within the extensive experimental noise research, noise has often been used as a convenient way of creating a stressful situation or to raise the arousal level. Thus the immediate objective has often been to test theoretical proposals with little direct relevance to the noise problems at the workplace. All the same, most of the hard

Institute of Occupational Safety and Health, Solna, Sweden.

Reprint requests to: Professor A Kjellberg, Institute of Occupational Safety and Health, S-171 84 Solna, Sweden. facts about noise effects emanate from such laboratory studies.

Which, then, are the psychological effects of interest? The most obvious is the subjective responses to noise, eg, annoyance or irritation. But noise may also change a person's behavior. It may lower performance level, and sometimes it also affects behavior towards other people. Finally, there may be psychophysiological counterparts to these subjective and behavioral responses; noise sometimes, eg, elicits physiological stress responses. These three types of effects are treated, in turn, in the following discussion.

\section{Subjective responses to noise}

In studies of subjective responses to noise subjects typically rate how loud, annoying, disturbing, etc, they find the noise. The relation between such estimates and various physical characteristics of the noise has been studied extensively, whereas the influence of other aspects of noise and of the situation is less well known. Another way of studying the subjective responses to noise is to make subjects describe their subjective state, eg, their mood, in the presence and the absence of noise. Mackay (1) used an instrument based on the two-dimensional stress-arousal model of mood and found that subjects were more distressed during noise exposure, whereas the effect on the activation dimension was less marked. However, such studies of mood are rather rare, and little can be said about the relation between such responses and various characteristics of noise.

\section{Critical physical characteristics}

The basic psychoacoustics, ie, the relation between the physical qualities of noise and the subjective response to it, are common knowledge and have been summarized by many authors (2). Therefore, they have been 
treated only briefly, stress being placed on the exceptions to the general rules.

Sound level. It is generally agreed that the loudness of a sound in most cases is doubled with each 10-dB increase in the sound pressure level. The most important exception to this rule is low-frequency noise. When, eg, a $100-\mathrm{Hz}$ tone is raised $10 \mathrm{~dB}$, it is experienced as four to five times louder (3).

Similar functions have been determined for more evaluative aspects of the subjective response to noise, like noisiness and annoyance (4). Generally, only small differences have been found between these functions. Thus a certain increase in the noise level usually increases loudness and annoyance to the same extent. However, when two different sounds are compared, the one with the lowest sound level may of course be the most annoying.

In reports of noise surveys in residential areas, the effect of noise level is often not described in terms of degree of annoyance but in terms of the percentage of the exposed who complain or experience a certain degree of annoyance. A typical finding in studies of traffic noise is that the percentage of annoyed people, above a threshold level, increases by about $10 \%$ for each 5-dB increase in the sound level (4).

Frequency. There is general agreement on the overall shape of the equal loudness curves, which describe the differential sensitivity of man to sounds of different frequencies. Thus the maximum sensitivity lies within the $500-5000 \mathrm{~Hz}$ frequency range, the sensitivity decreases rapidly in the lowest frequency band, and few persons hear any sounds above $15000 \mathrm{~Hz}$. A $100-\mathrm{Hz}$ tone must, eg, be presented at about $50 \mathrm{~dB}$ in order to be experienced as equally loud as a $40 \mathrm{~dB}$ tone of $1000 \mathrm{~Hz}$. The equal loudness curves become flatter at higher sound pressure levels, ie, the frequency dependency decreases when the level is raised. The frequency weighting filters which are normally used when noise is measured are based on such curves. However, it should be noted that the same filter, usually the A-filter, is used irrespective of sound level. This filter, yielding readings denoted as $\mathrm{dB}(\mathrm{A})$, is based upon the equal loudness curve at a very low level $(40 \mathrm{~dB})$, where the difference between the sensitivity to different frequencies is large. In other words the $\mathrm{dB}(\mathrm{A})$ value is influenced very little by the low-frequency components of the noise. A consequence, which is confirmed by several studies, is that the $\mathrm{dB}(\mathrm{A})$ value grossly underestimates the subjective impression of noise containing strong low-frequency components, eg, ventilation noise (5).

Contrary to popular belief, it is possible to hear sounds below $20 \mathrm{~Hz}$, ie, infrasound, if presented at high enough levels. (The auditory threshold lies around $95 \mathrm{~dB}$ at $16 \mathrm{~Hz}$ and $120 \mathrm{~dB}$ at $3 \mathrm{~Hz}$.) Infrasound is distinguished from higher frequencies in that a pure infrasound tone has subjectively no tonal quality but is experienced as beats. Infrasound may also give rise to vibrotactile sensation, but the threshold for it lies 15-30 dB above the hearing threshold (6).

Equal sensation curves have also been constructed for noisiness (4). Their general appearance is very similar to the loudness curves, but there is a more marked sensitivity maximum in the $2000-5000 \mathrm{~Hz}$ band. The D-weighting filter is based upon this curve, and it has been shown that $\mathrm{dB}(\mathrm{D})$ often gives a better prediction of annoyance than $d B(A)$, especially for noise containing strong low-frequency components (5).

Exposure time. The effects of the length of exposure to noise may be viewed in different perspectives. Considering first very short exposure times, it is known that, during a short period of about $0.1 \mathrm{~s}$, energy is integrated to create the impression one has of the loudness (temporal summation) (3). In other words a $10-\mathrm{ms}$ sound is less loud than a 100 -ms sound when the two are presented at the same sound pressure level. This 100 -ms integration time is built into the sound level meter and results in a better prediction of the subjective impression. However, an underestimation of the risk of hearing damage may sometimes occur since the integration time in the ear is less than 2 ms. Thus a very short sound (impulse noise) may cause damage to the ear without being experienced as very loud (7). In such a case the subjective response does not constitute an adequate warning for risks of damage.

The second perspective concerns how the subjective impression changes when exposure is prolonged up to several hours. In many sense modalities a rather dramatic adaptation occurs. This does not seem to be the case for sound, except at near threshold levels. Thus loudness generally does not seem to be lower after $1 \mathrm{~h}$ than after $1 \mathrm{~s}(3)$.

Finally, it is commonly believed that in a long-term perspective people will adapt to noise in the sense that they become less annoyed by it. In fact, most evidence speaks against such an effect (8), at least after the first few weeks in a new environment. A study by Weinstein (9) even indicates that the annoyance of those who are initially most annoyed by the noise undergoes the opposite change; their annoyance increases with exposure time.

Temporal variability. The risk for hearing damage is usually less if the noise varies over time than if it is constant. If anything, the opposite is true for subjective reactions to noise. Variability is in itself an annoying characteristic of noise $(10,11)$. A very sudden increase in noise level is especially annoying (4).

Signal-noise ratio. The most obvious effect of noise is that it may mask speech and other sounds which one 
wants to hear. Several studies have shown that noise is especially annoying when this is the case $(12,13)$.

However, masking may sometimes have a positive effect, by making unwanted sounds less intrusive. Faint intermittent sounds, like dripping water, may become very annoying if heard in an otherwise very quiet environment. In such cases a continuous masking noise would probably decrease the annoyance. The same is true of speech masking. Sometimes a higher background level is preferred if it prevents a person from overhearing irrelevant conversations. This effect naturally also operates in the other direction, ie, by preventing others from hearing a conversation, noise also protects privacy.

\section{Other factors influencing the subjective response to noise}

In studies of noise annoyance in residential areas physical noise measures have generally been found to explain a very small percentage of the interindividual variance in annoyance $(14,15)$. There is a lack of comparable data from occupational environments, but in a methodological study (16) it was possible to explain about $25 \%$ of the variance in the most favorable case and only $14 \%$ in the least favorable. These results may partly be explained by shortcomings in the annoyance and noise measurements, but it is also evident that nonphysical noise characteristics are of great importance. Unfortunately, research on the influence of such factors on subjective response is rare and virtually nonexistent with respect to the work environment. Therefore, the factors presented in this paper have rarely been subjected to any systematic studies, although they are often mentioned as critical. They also constitute possible explanations of observed group differences with respect to noise annoyance.

Informational content. In many work environments complaints about noise most commonly concern irrelevant speech (17). Probably the informational content of the speech is the main determinant of its intrusiveness. However, there is some support from performance data that even incomprehensible speech sounds are especially intrusive (18). However, no systematic studies have been reported on the relative importance of various speech features on subjective effects.

Sounds other than speech may of course also carry information which makes them more or less acceptable, eg, that something is wrong with a machine.

Predictability and controllability. Results from stress research indicate that an unpredictable and uncontrollable stressor generally yields a stronger stress response than a predictable and controllable event (19). A predictable stressor offers greater possibilities to prepare oneself and also implicates that there are periods during which the person does not have to be prepared for the stressor. Accordingly, an expected noise is generally judged as less annoying than an unexpected one. Similarly, the person who operates a machine and thus controls its noise is generally less annoyed by it than are other people exposed to the same noise.

Attitude towards the noise source. A person's response to noise is also influenced by his or her attitude towards the source of the noise. McKennell (20), eg, found that the persons least annoyed by the noise from the Concorde airplane were those who had the strongest patriotic feelings for the Concorde project. Likewise, Sörensen (21) managed to reduce the complaints about aircraft overflights by creating a more positive attitude towards the air force.

It is reasonable to assume that the same mechanisms are at work also in occupational settings. Thus one would, eg, expect a secretary who does not like word processors to be especially irritated by the printer noise.

Ongoing activity. It is often assumed that annoyance response depends on the task in which one is engaged. However, no studies have been reported on the importance of task characteristics other than vulnerability to masking effects. Thus there is no empirical basis for the often expressed view that the different types of activities in factories and offices may explain why higher levels are tolerated in factories.

Aspiration level and the "necessity" of the noise. In a workshop most of the noise is generally regarded as an unavoidable consequence of the activity, whereas the same noise would be considered unnecessary in an adjacent office. This is probably the main reason why a noise deemed acceptable in a workshop would be regarded as unbearable in an office. The importance of aspiration levels and the avoidability of the noise has never been studied in occupational environments, but it has been shown to be an important factor for noise response in residential areas (22).

Individual differences. It is obvious that the same noise elicits widely different responses from different persons. Much research has been devoted to these individual differences, and it has mainly concerned the following three questions: (i) are there any stable individual differences with respect to the subjective response to noise; (ii) if so, is it a case of specific noise sensitivity; and (iii) finally, what characterizes noise sensitive persons? A comprehensive review of the studies on individual differences has been written by Jones \& Davies (23).

The first problem encountered when one tries to study individual differences is how the sensitive individuals should be identified. One strategy has been 
to find the individuals who give extremely high annoyance ratings in relation to their exposure levels. Such ratings do not of course reflect only stable individual characteristics, but also response styles, situational differences, and transient states. Another strategy is to ask directly how sensitive the persons consider themselves. Irrespective of the method used, the validity and reliability of the sensitivity index will create problems of interpretation.

Although it has been claimed that the distribution of noise sensitivity is bimodal (24), most evidence indicates a normal distribution (25). The persons who appear to be sensitive to noise thus probably constitute the upper part of a normal distribution of individual responses. The question remains regarding the extent to which these differences may be attributed to stable individual differences in noise sensitivity. The low test-retest reliabilities of annoyance ratings indicate that, to a large degree, they reflect transient states rather than stable traits (26). On the other hand, Weinstein (9) found that students who reported themselves to be noise sensitive before arriving at college were also much more bothered by dormitory noise.

However, there are reasons to doubt that the stable differences in annoyance reflect a specific noise sensitivity. Thus, in a later study, Weinstein (27) found substantial correlations between the evaluations of different aspects of the neighborhood. He also found that a critical tendencies scale (that did not include any questions on noise) predicted noise annoyance as well as a noise sensitivity scale did. Thus noise sensitivity as a specific and stable trait has little support in data.

What characterizes those most annoyed by noise? The very inconsistent results indicate, eg, that there are no simple sex and age differences in noise sensitivity (27). There is some support for associations between different personality traits and noise sensitivity (23), but, again, it is possible that the noise sensitivity measure should rather be viewed as a measure of general annoyance (25).

One group which definitely deviates from others in response to noise comprises those with a hearing impairment. Contrary to popular belief these people are not necessarily less sensitive to noise than those with normal hearing. Quite the opposite, they are often more annoyed by noise than others. There are two reasons for this sensitivity. One is the recruitment phenomenon, which means that, although their hearing thresholds are higher than those of an unimpaired person, the loudness of sounds well above the threshold may be normal. Thus, for an impaired person, the growth of loudness is abnormally rapid when the level is raised well above the threshold. Therefore sounds with a varying sound level, eg, speech, become distorted and more annoying.

The other reason for more severe annoyance responses among those with impaired hearing is that the impairment is followed by strengthened masking effects. In other words, much lower noise levels be- come annoying as a consequence of their interfering with, eg, speech intelligibility (28).

\section{Behavioral effects of noise}

The behavioral effect of noise which has attracted most attention is the effects on performance, and the present section thus deals primarily with these effects. The studies of social behavior during noise exposure are, however, mentioned briefly.

\section{Theoretical interpretations of the performance effects}

Masking. It is an undisputable fact that the performance of any task which involves auditory cues may be deteriorated by noise. Poulton (29) has claimed this situation to be true of almost all reported negative effects of continuous noise. Thus, according to him, these effects may be explained by the masking of auditory feedback or inner speech. Broadbent (30) has convincingly argued against these ideas and showed that they leave many effects unexplained. However, Poulion must be credited for calling attention to the importance of the masking of auditory cues also in tasks which are not primarily of an auditory nature.

Distraction. Any sudden change in the environment may disrupt ongoing activity. This statement is of course also true with respect to the onset and offset of noise. Distraction may also be important for the negative effects of variable and meaningful noise (eg, irrelevant speech).

Arousal level, allocation of attention. The effects of noise on performance have usually been treated within the framework of arousal theory, sometimes supplemented by the hypothesis that attention becomes more selective at high arousal levels. Generally speaking, noise has been supposed to raise the arousal level, but there is reason to believe that continuous or repetitive noise sometimes makes people sleepy $(6,31,32)$. The main support for the arousal theory has been provided by studies in which noise has been found to alleviate the effects of dearousing factors like sleep deprivation (33).

One problem encountered by arousal theory is the fact that small changes in the task or the experimental situation may alter the results dramatically. Thus experimental results by no means present a simple and consistent picture of the effects of noise. This fact has cast doubts upon the rather mechanistic arousal theory and has been used as an argument for a "strategy choice theory," which states that noise influences the way in which a person chooses to carry out a task (34, 35 ). In other words, eg, attentional selectivity is not regarded as an inevitable consequence of the arous- 
ing effects of noise, but as one of many factors which may increase the mental load and make the task more difficult to perform. In such a situation the available information processing resources are likely to be directed towards the most important aspects of the task at the expense of the less important ones. This is not to deny that some of the performance effects are unavoidable consequences of the noise exposure. This statement is primarily true of those consequences brought about by masking effects, but it is also conceivable that some of the effects on short-term verbal memory are a result of direct and unavoidable interference with a stage of information processing.

\section{Field studies of safety and efficiency}

The few studies treating the effects of noise on safety and efficiency at workplaces indicate that high noise levels are associated with higher accident rates (36) and lower productivity or higher error rates $(37,38)$. However, the interpretation of these results is complicated by the fact that high-noise work settings are likely to be defective also in other respects. A certain control over such confounding factors may be attained through the study of the effects of noise reduction. However, when Noweir (38) found that a reduction in noise level led to higher productivity, it may have been a result of the management showing an interest in improving the environment, rather than of the noise reduction in itself. The reduced accident rate as a result of wearing ear protectors shown by Cohen (39) is less likely to be an effect of such factors. The same is true of the reduced error rate found by Broadbent \& Little (37) in a factory producing motion picture films. In this factory workers alternated between two rooms, one of which was treated acoustically. Operator errors were substantially reduced in this room but not in the other one. Reduced masking effects may be one explanation for this outcome, but attentional effects might also have been of importance.

\section{Noise effects in different tasks}

Noise is relatively easy to produce in the laboratory, and this is probably a major reason for the vast amount of laboratory research on noise and performance in comparison with research on other factors of the physical environment, such as climate or vibration. The results have by no means been consistent, as is reflected in the fact that reviewers of this topic have drawn at least apparently conflicting conclusions. Thus Kryter (4) concluded that there are no significant nonauditory adverse effects of noise on performance, whereas the conclusion in another review covering the same period (40) was that recent research "suggested that a much wider range of mental functions than hitherto supposed is influenced by noise [p 131].",

Another general point to be made before the results are reviewed is that many of the studies in this area have dealt with noise at levels which are, or should be, avoided for reasons of hearing protection. Since these studies are of limited practical interest, they will only be treated briefly.

Tasks in which noise may improve performance. It follows from arousal theory that noise should improve performance in situations when the task in itself lowers the arousal level. As shown by Poulton (41), several studies have obtained such an effect of noise at moderate levels, primarily with the use of variable noise and long simple monotonous signal monitoring tasks. However, the evidence is not as consistent as Poulton indicates (42). Noise has also been found to improve recall in some memory tasks (43), but this effect is generally not viewed as an arousal effect.

Tasks insensitive to continuous meaningless noise. The performance of several types of tasks appears to be unaffected even by very high levels of continuous noise. Examples of such tasks mentioned by Broadbent (44) are simple reaction-time tasks with an easily discriminable and fore-warned stimulus, motor performance, and sensory tasks such as visual acuity tasks.

\section{Tasks sensitive to noise}

Reaction-time and vigilance tasks. The five- or fourchoice serial reaction-time task is probably the task used in most noise studies (40). Typically the task consists of five lights above five response buttons, and a new bulb lights up immediately after a response has been made to the previous one. The typical effect of noise on this type of task is an increased number of fast erroneous responses. Furthermore, this effect of noise, like most other effects on performance, is accentuated with increased time in the task. The increased error rate probably reflects impaired control processes during noise exposure (45), more specifically a lowered ability to withhold a highly prepared response to an anticipated signal. In many of these studies very high noise levels were used, but Smith \& Miles (46) showed that, when exposure time is prolonged, the effect is obtained also at moderate noise levels.

The serial reaction task has also been used to study the effects of noise on the allocation of attention (47). Smith found that the difference between response times to the signals with high and low probability was accentuated by noise, ie, attention was concentrated on the most probable stimuli at the expense of the less probable ones. The same experiment also showed that subjects were less flexible in noise, in the sense that they adapted more slowly to a change of signal probabilities. A similar effect in a cognitive task was reported by Dornic \& Fernaeus (48).

Earlier studies of tasks requiring the monitoring of infrequent and weak signals, vigilance tasks, found detrimental effects only at very high noise levels and 
only in tasks requiring the monitoring of several signal sources or the simultaneous performance of another task. The effects observed by, eg, Hockey (49) have usually been consistent with the view that noise increased attentional selectivity.

Later studies have shown that vigilance performance may be impaired by noise also at lower levels, provided that the signal is of a more complicated nature, eg, makes demands on memory by requiring the identification of a certain series of signals (50).

Text comprehension and other verbal tasks. Recent research has demonstrated that noise may affect performance at levels previously considered harmless. One reason for this phenomenon has been a shift of interest from sensorimotor tasks to verbal tasks. Evidence from different kinds of studies indicates that noise may lead to a more superficial processing of the text and, thus, to impaired comprehension. Hockey (51) reports that noise even improved the memory of inconsequential details in a text, but impaired the comprehension of the content of the text. Similar effects were reported by Jones \& Broadbent (52).

A more indirect demonstration of the same effects is found in the proof reading experiments by Weinstein $(53,54)$. Noise had no effect on the identification of simple typographical errors, but lowered the detection frequency of the more complicated errors, which required comprehension of the text for their identification.

Some conventional memory experiments using lists of words also indicate that the interpretation of a text may be more superficial in noise. Subjects tend to keep semantically related words together when reporting such a list. This tendency has been found to be weaker when learning takes place in noise $(55,56)$

Irrelevant speech and verbal short-term memory. The impaired verbal short-term memory in the presence of irrelevant speech demonstrated by Salamé \& Baddeley (57) and reviewed by Jones (18) has been found to be an unusually consistent effect. The main conclusions from this research are that the effect is independent of speech level [at least between 55 to $95 \mathrm{~dB}(\mathrm{~A})$ ] and that it appears also when speech is incomprehensible to the subject. It is unlikely that distraction effects could explain the impairment, which rather seems to depend on direct interference with memory processes.

Incidental learning. Hockey \& Hamilton (58) instructed their subjects to remember words presented on different parts of a screen. This task was accomplished at least as well in noise as in a control situation. However, when subjects were unexpectedly asked to remember the location of the words, more errors occurred in the noise group. Other studies of such incidental learning have obtained the same result $(59,60)$. Thus these results provide further evidence of noise leading to an increased concentration of attentional resources on the aspects of the tasks deemed most important.

\section{Effects of noise characteristics}

Noise level. Noise level is the only physical noise characteristic which has been studied to any extent. Broadbent (44) concluded that negative effects on performance were only to be expected at very high levels [somewhere between 90 and $95 \mathrm{~dB}(\mathrm{~A})$ ]. Since then researchers have become increasingly aware of the complexity of the matter, and no general conclusions about the critical level now seem possible. It obviously depends on the nature of the task, the experimental setting, and the choice of subjects and their experience. Sometimes the critical level is very low, as shown by the studies of irrelevant speech and by Kjellberg \& Wide (61), who found performance effects of continuous noise at $51 \mathrm{~dB}(\mathrm{~A})$. The issue is further complicated by problems of generalization from laboratory to real work conditions, in which the duration of exposure and work is so much longer.

Frequency. Only Broadbent (62) has specifically treated the effects of sound frequency on performance. He found that serial reaction-time performance was more sensitive to high- than to low-frequency noise.

Duration. Generally the effect of noise has been found to increase as a function of time on a task. This finding is not necessarily an effect of exposure time in itself but is perhaps better described as an effect of working for a long time in noise, ie, an interaction effect. However, in two studies, subjects were exposed to noise for a longer or shorter period before the task (63, 64). These studies indicate that there may also be an effect of exposure time in itself.

Variability, predictability, control. Intermittent noise has generally been found to impair performance more than continuous noise (65), especially if the time schedule is unpredictable (66). The opposite effect may be obtained if the subject is well acquainted with the noise and the time schedule is reasonably predictable (67). In the one study which treated the effect of subjects having control over noise level (68), performance was less disrupted when subjects had, or rather thought they had, control.

\section{Aftereffects of noise}

In their influential book Urban Stress, Glass \& Singer (69) reported a series of studies which indicated that performance may be impaired also after a period of noise exposure. A review of more recent studies has been given by Cohen (70). The tasks which seem to 
be most sensitive to the aftereffects of noise do not primarily measure the capacity to perform, but rather the motivation to perform well, eg, endurance in unsolvable tasks or tasks which are very dull or difficult. In contrast to acute effects, aftereffects have been found to be very predictable. It is also to be noted that an acute effect during exposure is not a prerequisite for aftereffects.

Aftereffects are the most evident after exposure to uncontrolled or unpredictable noise, whereas they are less dependent on noise level. In fact, the aftereffects of noise should not be regarded as due to noise in itself but rather as due to a general influence of uncontrollable and unpredictable stressors (70).

The bulk of evidence on aftereffects comes from laboratory studies, and there seems to be no studies of the aftereffects of occupational exposure to noise. Several studies have, however, treated the aftereffects of noise in the classroom, and they indicate that the effects are not restricted to the laboratory (71).

\section{Other behavioral effects of noise}

Many studies indicate that people behave differently towards each other in noisy environments than elsewhere. One obvious reason for this occurrence is that noise makes speech communication more difficult, but this phenomenon does not explain all the social effects of noise. Thus a series of field experiments has shown that people tend to be less helpful in noise. (A review of these and other studies of the social effects of noise can be found in reference 72.) There are several possible reasons for such an effect, eg, that noise distracts attention from the person in need of help, that people want to get out of the noisy situation as fast as possible, or that the noise actually makes them irritated and less willing to help.

\section{Psychophysiological effects}

The physiological responses to noise are of three types, distinguished by their duration and their relation to the noise exposure. First, changes in noise may elicit short-lasting, phasic responses. Second, noise may give rise to more persistent, tonic responses during and for a short period after exposure. Finally, it is feasible that noise may cause more stable changes and constitute a long-term health hazard.

\section{Immediate phasic response to noise changes}

Any change in the environment and thus any change in noise (raised or lowered level, changed quality) may lead to an attentional response generally called the "orienting reflex," This response involves a redirection of sense organs towards the noise source, but also a series of physiological responses lasting one or a few seconds and including, eg, a lowered heart rate, blood pressure, and peripheral blood flow, along with in- creased sweat gIand activity. An important aspect of this response is that it habituates, provided that the noise is found to be of no importance for the individual. Habituation thus could be viewed as a primitive learning process implying learning not to respond to irrelevant stimulation or learning not to be distracted. This habituation is faster for low-level noise and for short intervals between the changes. There is also evidence of consistent differences between individuals with respect to habituation rate (73). More comprehensive reviews of the orienting reflex and other physiological responses of brief duration have been given by Graham (74) and Westman \& Walters (75).

Noise at very high levels (at least above $90 \mathrm{~dB}$ ) elicits a somewhat different response pattern, the defensive reflex, which does not habituate or, at least, habituates very slowly. If the noise has a very sudden onset, ie, short rise time, it may evoke a startle reflex, which, eg, includes blinking and muscular jerks. Some of the components of the reflex habituate fast, while others habituate slowly or not at all. Thus, eg, even an experienced shooter blinks when a shot is fired. Obviously, a startle response may cause a momentary disruption in the performance of manipulatory tasks (76).

These physiological responses of brief duration are very weak and of no consequence in themselves. Rather, their importance is as indicators of the distracting effects of noise.

\section{Persistent, tonic responses}

A second aspect of the psychophysiological responses to noise concerns whether, eg, heart rate, blood pressure, or catecholamine output is higher in a noisy environment than under more quiet circumstances. Studies of this problem have been reviewed by, eg, Borg (77) and Sandén \& Axelsson (78).

In the typical experiment physiological responses have been registered for resting persons exposed to high-level noise. These studies have generally revealed a peripheral vascular constriction and a raised diastolic blood pressure level during noise, whereas the effects on systolic blood pressure, pulse rate, and the output of "stress hormones" like cortisol or epinephrine have been less consistent. [See the review by Borg (77).]

In another, more relevant but less common, type of study physiological responses to noise have been observed during mental work. To the extent that noise makes the task more difficult, one would expect it to elicit responses indicating stress. Such an effect was found by Brandenberger et al (79) on cortisol plasma levels but not on catecholamine levels. In other studies effects on either epinephrine or norepinephrine were found (80), but the results have by no means been consistent. One possible reason for this inconsistency is illustrated by a couple of studies by Frankenhaeuser \& Lundberg $(81,82)$. In one study (82) they let their subjects do mental arithmetic during exposure to lowor high-level noise. They found no effect of noise on 
performance, but an increased excretion of epinephrine and an increased rated effort did occur. Obviously, the performance level was upheld at the price of increased physiological stress. In another study by the same authors, which was designed to induce a lower performance standard (83), the opposite result was obtained, ie, performance was impaired whereas the epinephrine level was unaffected by noise.

In physiological research little work has been conducted on the importance of different noise characteristics, with the exception of noise level. But control has been shown to be an important variable also in this context. Thus much stronger responses have been found to uncontrolled noise than to noise over which one has control (84).

Sleep. Sleep disturbance is an important effect of noise in residential areas, whereas it of course is of less importance in work settings. In this context it is of greater interest that noise might have aftereffects on sleep, ie, noise exposure during the day may disturb sleep during the night (85).

Noise may also have the opposite effect, ie, it may provoke sleep. This effect is especially likely for lowfrequency noise, as has been demonstrated by Landström and his collaborators (86). However, similar effects have also been obtained with other types of monotonous, repetitive sounds (31).

\section{Long-term health hazards}

Cardiovascular responses constitute the most prominent acute physiological responses to noise, and this fact has given rise to the hypothesis that cardiovascular diseases might be promoted by noise. A certain support for this hypothesis is offered by long-term animal studies showing that noise exposure, eg, may lead to permanently raised blood pressure, ie, hypertension (77).

An increased incidence of hypertension and other cardiovascular problems has also been found in several epidemiologic studies of groups occupationally exposed to noise, although there are several contradicting results. A review of these studies has been given by Borg (77).

Long-term cardiovascular effects have also been found in residential areas with, eg, aircraft noise (87) and among schoolchildren from noisy areas (88).

Since noise may cause annoyance and stress, it is reasonable to hypothesize that it also contributes to the development of mental illness. Most of the studies addressing this problem have been conducted in residential areas and have compared symptoms, use of psychotropic drugs, or admissions to mental health care units in high and low noise areas. [See the reviews by Cohen \& Weinstein (89) and Tarnopolsky \& Clark (90).] Although many studies have found a higher incidence of such indicators of psychiatric ill health in noisy areas, most evidence argues against noise being a major causal factor behind the observed differences. A few studies have also been reported from occupational settings (91), and they have shown a higher incidence of psychiatric symptoms among workers exposed to extremely high-intensity noise. However, a lack of adequate reference groups in this work makes it impossible to distinguish the effects of noise from those of other possible contributory factors. The interpretation of the results from the occupational studies is also complicated by the fact that psychiatric symptoms are much more common among people with a hearing impairment than among the general population (92).

\section{Concluding remarks}

The number of workplaces in which people are exposed to a high level of noise is decreasing in most countries, although many people still receive damage to their hearing at work. At the same time the noise level is raised at many previously quiet workplaces as a result of increased mechanization and automation. Thus ventilation systems, computers, printers, and other machines have led to an increased noise pollution in, $\mathrm{eg}$, offices. The problem in these cases is never the risk of hearing damage, but noise annoyance and its possible behavioral and physiological consequences. The importance of these effects has been recognized in residential settings for some time, and it becomes more and more urgent to pay serious attention to them at workplaces.

\section{References}

1. Mackay CJ. The measurement of mood and psychophysiological activity using self-report techniques. In: Martin I, Venables PH, ed. Techniques in psychophysiology. Chichester: John Wiley \& Sons, 1980: $501-62$.

2. Carterette EC, Friedman MP. Handbook of perception; vol 4 (Hearing). New York, NY: Academic Press, 1978.

3. Scharf B. Loudness. In: Carterette EC, Friedman MP, ed. Handbook of perception. New York, NY: Academic Press, 1978:187-242.

4. Kryter KD. The effects of noise on man. New York, NY: Academic Press, 1985.

5. Kjellberg A, Goldstein M. Loudness assessment of band noise of varying bandwidth and spectral shape: an evaluation of various frequency weighting networks. J Low Freq Noise Vib 1985;4:12-26.

6. Landström U, Lundström R, Byström M. Exposure to infrasound - perception and changes in wakefulness. J Low Freq Sound Vib 1983;2:1-11.

7. Brüel PV. Do we measure damaging noise correctly? Noise Control Eng 1977;8:52-60.

8. Weinstein ND. Community noise problems: evidence against adaptation. J Environ Psychol 1982;2:87-97.

9. Weinstein ND. Individual differences in reactions to noise: a longitudinal study in a college dormitory. J Appl Psychol 1978;63:458-66.

10. Kuwano S, Namba S, Nakajima Y. On the noisiness of steady state and intermittent noises. J Sound Vib 1980;72:87-96.

11. Keighley EC. Acceptability criteria for noise in large offices. J Sound Vib 1970;11:83-93. 
12. Moran SLV, Loeb M. Annoyance and behavioral aftereffects following interfering and noninterfering aircraft noise. J Appl Psychol 1977;62:719-26.

13. Williams CE, Stevens KN, Klatt M. Judgements of the acceptability of aircraft noise in the presence of speech. J Sound Vib 1969;9:263-75.

14. Griffiths ID, Langdon FJ. Subjective response to road traffic noise. J Sound Vib 1968;8:16-32.

15. McKennel AC. Aircraft noise annoyance around London (Heathrow) airport. London: Her Majesty's Stationary Office, 1963.

16. Kjellberg A, Landström U, Löfstedt P, Wide P, Ảkerlund $\mathrm{E}$. Bedömning av upplevd bullerstörning $\mathrm{i}$ arbetet [Evaluation of noise and annoyance in working environments: a methodological study]. Solna (Sweden): National Institute of Occupational Health, 1988. (Arbete och Hälsa 1988:30.)

17. Nemecek J, Grandjean E. Results of an ergonomic investigation of large-space offices. Hum Factors 1973; 2:111-24.

18. Jones DM. Progress and prospects in the study of performance in noise. In: Berglund B, Berglund U, Karlsson J, Lindvall T, ed. Proceedings of the 5th international congress on noise as a public health problem; vol 4. Stockholm: Byggforskningsrådet (in press).

19. Thompson SZ. Will it hurt less if I can control it? A complex answer to a simple question. Psychol Bull 1981; 90:89-101.

20. McKennell AC. Annoyance from Concorde flights around Heathrow. In: Tobias JV, Jansen G, Ward WD, ed. Proceedings of the third international congress on noise as a public health problem. Rockville, MD: American Speech-Language-Hearing Association, 1980:5626.

21. Sörensen S. On the possibilities of changing the annoyance reaction to noise by changing the attitudes to the source of annoyance. Nord Hyg Tidsk 1970;(suppl 1): $76 \mathrm{p}$

22. Borsky PN. Review of community response to noise. In: Tobias JV, Jansen G, Ward WD, ed. Proceedings of the third international congress on noise as a public health problem. Rockville, MD: American SpeechHearing-Language Association, 1980:453-74. (ASAH reports 10 .)

23. Jones DM, Davies DR. Individual and group differences in the response to noise. In: Jones DM, Chapman AJ, ed. Noise and society. Chichester: John Wiley \& Sons, 1984:125-53.

24. Bryan ME, Tempest $\mathrm{W}$. Are our noise laws adequate? Appl Acoust 1973;6:219-32.

25. Thomas JR, Jones DM. Individual differences in noise annoyance and the uncomfortable loudness level. J Sound Vib 1982;82:289-304.

26. Griffiths ID, Delanzun FR. Individual differences in sensitivity to traffic noise: an empirical study. J Sound Vib 1977;55:93-107.

27. Weinstein ND. Individual differences in critical tendencies and noise annoyance. J Sound Vib 1980;68:241-8.

28. Aniansson G, Pettersson K, Peterson Y. Traffic noise annoyance and noise sensitivity in persons with normal and impaired hearing. J Sound Vib 1983;88:85-97.

29. Poulton EC. Continuous intense noise masks auditory feedback and inner speech. Psychol Bull 1977;84: 977-1001.

30. Broadbent DE. The current state of noise research: reply to Poulton. Psychol Bull 1978;85:1052-67.

31. Bohlin G. Monotonous stimulation, sleep onset and habituation of the orienting reaction. Electroencephalogr Clin Neurophysiol 1971;31:593-601.

32. Hartley LR. Similar and opposing effects of noise on performance. In: Ward WD, ed. Proceedings of the second international congress on noise as a public health problem. Washington, DC: Environmental Protection Agency, 1973:379-87.
33. Wilkinson RT. Interaction of noise with knowledge of results and sleep deprivation. J Exp Psychol 1963;66: 332-7.

34. Smith AP. The effects of noise on strategies of human performance. In: Rossi G, ed. Proceedings of the fourth international congress on noise as a public health problem. Milano: Centro Ricerche e Studi Amplifon, 1983: 797-807.

35. Smith A. A review of the effects of noise on human performance. Scand J Psychol (in press).

36. Wilkins PA, Acton WI. Noise and accidents - a review. Ann Occup Hyg 1982;25:249-60.

37. Broadbent DE, Little EAS. Effects of noise reduction in a work situation. Occup Psychol 1960;34:133-40.

38. Noweir MH. Noise exposure as related to productivity, disciplinary actions, absenteeism, and accidents among textile workers. J Safe Res 1984;15:163-74.

39. Cohen A. The influence of a company hearing conservation program on extra-auditory problems in workers. J Safe Res 1976;8:146-62.

40. Davies DR, Jones DM. Noise and efficiency. In: Tempest W, ed. The noise handbook. New York, NY: Academic Press, 1985:87-141.

41. Poulton EC. Arousing environmental stresses can improve performance, whatever people say. Aviat Space Environ Med 1976;47:1193-204.

42. Koelega HS, Brinkman JA. Noise and vigilance: an evaluative review. Hum Factors 1986;28:465-81

43. Breen-Lewis $\mathbf{K}$, Wilding $\mathbf{J}$. Noise, time of day and test expectations in recall and recognition. $\mathrm{Br} \mathrm{J}$ Psychol 1984;75:51-63.

44. Broadbent DE. Human performance and noise. In: Harris CM, ed. Handbook of noise control. New York, NY: McGraw-Hill, 1979:17:1-17:20.

45. Rabbitt P. Current paradigms and models in human information processing. In: Hamilton V, Warburton DM, ed. Human stress and cognition. New York, NY: John Wiley \& Sons, 1979:115-40.

46. Smith A, Miles $C$. The combined effects of noise and nightwork on human function. In: Oborne DJ, ed. Contemporary ergonomics 1985: proceedings of the Ergonomics Society's annual conference 1985 in Nottingham. London: Taylor \& Francis, 1985:33-41.

47. Smith AP. Noise, biased probability and serial reaction. Br J Psychol 1985;76:89-95.

48. Dornic S, Fernaeus SE. Type of processing in high-load tasks: the differential effect of noise. Stockholm: Department of Psychology, University of Stockholm, 1981. (Report no 576.)

49. Hockey GRJ. Effect of loud noise on attentional selectivity. Q J Exp Psychol 1970;22:28-36.

50. Jones DM, Smith AP, Broadbent DE. Effects of moderate intensity noise on the Bakan vigilance task. J Appl Psychol 1979;64:627.

51. Hockey GRJ. Stress and the cognitive components of skilled performance. In: Hamilton V, Warburton DM, ed. Human stress and cognition. New York, NY: John Wiley \& Sons, 1979: 141-77.

52. Jones DM, Broadbent DE. Side effects of interference with speech by noise. Ergonomics 1979;22:1073-81.

53. Weinstein ND. Effects of noise on intellectual performance. J Appl Psychol 1974;59:548-54.

54. Weinstein ND. Noise and intellectual performance: a confirmation and extension. J Appl Psychol 1977;62: 104-7.

55. Daee S, Wilding JM. Effects of high intensity white noise on short-term memory for position in a list and sequence. Br J Psychol 1977;68:335-49.

56. Smith AP, Broadbent DE. The effects of noise on recall and recognition of instances of categories. Acta Psychol 1982;51:257-71.

57. Salam P, Baddeley A. Noise, unattended speech and short-term memory. Ergonomics 1987;30:1185-94.

58. Hockey GRJ, Hamilton P. Arousal and information 
selection in short-term memory. Nature 1970;226: 866-7.

59. Cohen S, Lezak A. Noise and inattentiveness to social cues. Environ Behav 1977;9:559-72.

60. Davies DR, Jones DM. The etfects of noise and incentives upon attention in short-term memory. $\mathrm{Br} \mathrm{J}$ Psychol 1975;66:61-8.

61. Kjellberg A, Wide P. Effects of simulated ventilation noise on performance of a grammatical reasoning task. In: Berglund B, Berglund U, Karlsson J, Lindvall T, ed. Proceedings of the 5 th international congress on noise as a public health problem; vol 3. Stockholm: Byggforskningsrådet, $1988: 31-6$.

62. Broadbent DE. Effects of noises of high and low frequency on behaviour. Ergonomics 1957;1:21-9.

63. Hartley LR. Performance during continuous and intermittent noise and wearing ear protection. J Exp Psychol 1974;102:512-6.

64. Smith AP, Broadbent DE. The effects of noise on the naming of colours and reading of colour names. Acta Psychol 1985;58:275-85.

65. Smith AP. The effects of different types of noise on semantic processing and syntactic reasoning. Acta Psychol 1985;58:263-73.

66. Kohfeld DL, Goedecke DW. Intensity and predictability of background noise as determinants of simple reaction time. Bull Psychon Soc 1978;12:129-32.

67. Warner HD, Heimstra NW. Effects of intermittent noise on visual tasks of varying complexity. Percept Mot Skills 1971;32:219-26.

68. Blechman EL, Dannemiller EA. Effects on performance of perceived control over noxious noise. J Consult Clin Psychol 1976;44:601-7.

69. Glass DC, Singer JE. Urban stress: experiments on noise and social stressors. New York, NY: Academic Press, 1972.

70. Cohen S. Aftereffects of stress on human performance and social behavior: a review of research and theory. Psychol Bull 1980;88:82-108.

71. De Joy DM. Environmental noise and children: review of recent findings. J Aud Res 1983;23:180-94.

72. Cohen S, Spacapan S. The social psychology of noise. In: Jones DM, Chapman AJ, ed. Noise and society. Chichester: John Wiley \& Sons, 1984:221-45.

73. Lader M. The psychophysiology of anxious and depressed patients. In: Fowles DC, ed. Clinical applications of psychophysiology. New York, NY: Columbia University Press, 1975:12-41.

74. Graham FK. Distinguishing among orienting, defense, and startle reflexes. In: Kimmel HD, van Holst EH, Orbleke JF, ed. The orienting reflex in humans. New York, NY: Lawrence Erlbaum, 1979:137-67.

75. Westman JC, Walters JR. Noise and stress: a comprehensive approach. Environ Health Perspect 1981;41: 291-309.

76. May DN, Rice CG. Effects of startle due to pistol shots on control precision performance. J Sound Vib 1971; 15:197-202.

77. Borg E. Physiological and pathogenic effects of sound. Acta Otolaryngol 1981;(suppl 381): 68 p.

78. Sandén Å, Axelsson A. Comparison of cardiovascular responses in noise-resistant and noise-sensitive workers. Acta Otolaryngol 1981;(suppl 331):75-100.

79. Brandenberger G, Follenius M, Wittersheim G, Salame P, Siméoni M, Reinhart B. Plasma catecholamines and pituitary adrenal hormones related to mental task demand under quiet and noise conditions. Biol Psychol 1980;10:239-52.

80. Klotzbücher E. Zum Einfluss des Lärms auf Leistung bei geistiger Arbeit und ausgewählte physiologische Funktionen. Int Arch Occup Environ Health 1976;37: 139-55.

81. Frankenhaeuser M, Lundberg U. Immediate and delayed effects of noise on performance and arousal. Biol Psychol 1974;2:127-33.

82. Lundberg U, Frankenhaeuser M. Psychophysiological reactions to noise as modified by personal control over noise intensity. Biol Psychol 1978;6:51-9.

83. Frankenhaeuser $M$, Lundberg $U$. The influence of cognitive set on performance and arousal under different noise loads. Motiv Emotion 1977;1:139-49.

84. Breier A, Albus M, Pickar D, Zahn TP, Wolkowitz. OM, Paul SM. Controllable and uncontrollable stress in humans: alterations in mood and neuroendocrine and psychophysiological function. Am J Psychiatry 1987;144: $1419-25$.

85. Fruhstorfer B, Fruhstorfer H, Grass P, et al. Daytime noise and subsequent night sleep: interference with sleep patterns, endocrine functions and serotogenic system. In: Rossi G, ed. Proceedings of the fourth international congress on noise as a public health problem. Milano: Centro Ricerche e Studi Amplifon, 1983:1015-8.

86. Landström $U$, Byström M, Nordström B. Changes in wakefulness during exposure to noise at $42 \mathrm{~Hz}, 1000 \mathrm{~Hz}$ and individual EEG frequencies. J Low Freq Sound Vib $1985 ; 4: 27-33$.

87. Knipschild PV. Medical effects of aircraft noise: community cardiovascular survey. Int Arch Occup Environ Health 1977;40:185-90.

88. Cohen S, Evans GW, Krantz DS, Stokols D. Physiological, motivational, and cognitive effects of aircraft noise on children. Am Psychol 1980;35:231-43.

89. Cohen S, Weinstein N. Nonauditory effects of noise on behavior and health. J Soc Issues 1981;37:36-70.

90. Tarnopolsky A, Clark C. Environmental noise and mental health. In: Freeman $H$, ed. Mental health and the environment. London: Church \& Livingstone, 1984: 250-70.

91. Miller JD. Effects of noise on people. J Acoust Soc Am 1974;3:729-64.

92. Singerman B, Riedner E, Folstein M. Emotional disturbance in hearing clinic patients. Br J Psychiatry 1980; $137: 58-62$. 